Research Article

\title{
The Effect of Thermal Cycling on the Tensile and Shear Behaviors of the Carbon Nanotube-Reinforced Epoxy
}

\author{
Ali Anvari iD and Sanjeev Khanna \\ Department of Mechanical and Aerospace Engineering, University of Missouri-Columbia, Columbia, Missouri 65211, USA \\ Correspondence should be addressed to Ali Anvari; aabm9@mail.missouri.edu
}

Received 5 August 2021; Revised 28 August 2021; Accepted 4 September 2021; Published 30 September 2021

Academic Editor: Antonio Concilio

Copyright (c) 2021 Ali Anvari and Sanjeev Khanna. This is an open access article distributed under the Creative Commons Attribution License, which permits unrestricted use, distribution, and reproduction in any medium, provided the original work is properly cited.

\begin{abstract}
The aim of this research is to study the tensile and shear properties and mechanical behavior of carbon nanotube- (CNT-) reinforced epoxy after the resulting composites have been exposed to different thermal cycling environments. Single-walled carbon nanotubes (SWCNTs) are cylindrical molecules that consist of rolled-up sheet of single-layer carbon atoms (graphene) with a diameter of less than 1 nanometer $(\mathrm{nm})$. Thermal cycling environments can exist in many conditions, such as in-earth orbit for satellites which rotate around the earth and pass through the sun illumination and earth's shadow, and for airplanes which fly in different altitudes with different temperatures. Carbon nanotube-reinforced epoxy is one of the nanocomposite materials which have been broadly used in many applications such as aerospace, automotive, electronics, and other industries. The goal of this study is to fabricate this nanocomposite with different multiwall and single-wall CNT concentrations and expose it to different thermal cycle numbers and determine the changes in tensile and shear properties and failure characteristics. For this purpose, tension and short-beam tests have been used in this research. The addition of multiwall CNT produces better mechanical properties compared to the use of SWCNT reinforcement. However, unreinforced epoxy showed the highest mechanical properties.
\end{abstract}

\section{Introduction}

Lijima has been the first scientist that introduced the CNTs [1]. CNTs are cylindrical molecules that consist of rolled-up sheets of single-layer carbon atoms (graphene). CNTs have been applied in different industries such as electronics, aerospace, and automotive. The reasons that CNTs have attracted many industries are the excellent mechanical properties such as high aspect ratio, high Young's modulus, and high tensile strength [2]. Due to the mentioned CNT properties, recently, many experiments and studies have been conducted to analyze the structure, mechanics, and synthesis of the CNTs [3-7]. Furthermore, currently in the area of new material's characterization, an article has been published [8].

There are different methods to produce CNTs such as chemical vapor deposition, electric arc discharge, catalyst arrays, sonochemistry, electrolysis, and laser ablation. Many studies have indicated that the production method has an effect on the geometry of CNT because it can change the diameter and length of the CNT. The alteration in the geometry of CNT can change the mechanical properties, failure mechanism, surface interaction, and reactivity of it [2].

Application of CNTs within the matrix can enhance the stiffness and improve the toughness $[9,10]$. It is required to have CNTs dispersed uniformly within the matrix to prevent from stress concentration within the CNT agglomerated areas and have the uniform mechanical properties within the entire nanocomposite. For this purpose, chemical treatment with the ultrasonication process can be applied.

CNTs can be in the form of single-walled CNTs (SWCNTs) and multiwalled CNTs (MWCNTs). The diameter of CNT is about a few nanometers, while the length of 


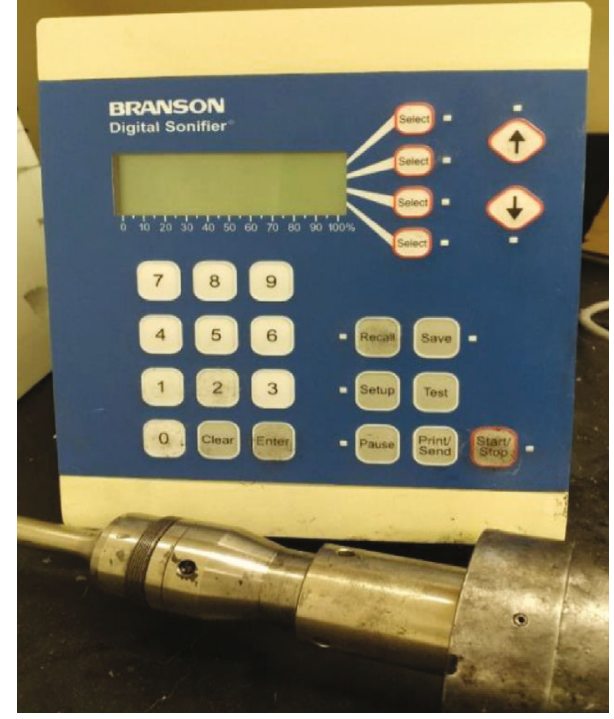

Figure 1: Ultrasonicator equipment which has been used to mix the CNTs with epoxy.

CNT is about a few microns. Epoxy is a great candidate for the matrix material. The reasons are the high chemical and corrosion resistance, great tensile strength, and high adhesion and dimensional stability. Therefore, CNT-reinforced epoxy (CNT/epoxy) with the combination of the mechanical properties of CNT and epoxy is a great candidate to apply in many industries such as aeronautics, electronics, and astronautics.

While applying the CNT/epoxy in the thermal cycling environment, cracks could form within the nanocomposite especially within the CNT agglomerated areas due to stress concentration. CNT agglomeration occurs due to the Van der Waals force between them. Consequently, the crack propagation caused after repeated thermal cycles can cause the CNT/epoxy to fracture.

Since, while satellites rotate around the earth, they pass through the sun illumination and solar eclipse, they are exposed to temperature variation which can develop thermal cycling; an exact analysis to investigate the effect of thermal cycling on the mechanical behavior of carbon nanotube-reinforced epoxy is required [11, 12]. Furthermore, the same phenomenon occurs while airplanes take off and land. The reason is, at different altitudes, temperature changes which can develop thermal cycling. Furthermore, in other industries such as automotive, thermal cycling exists. Each time an automobile turns on, it heats up, and each time it turns off, it cools down. As a result, a thermal cycle will be created. A relevant study that has been done in 2012 by Park et al. [13] measured the mechanical properties degradation of carbon fiber-reinforced epoxy composite that were exposed to 2000 thermal cycles. In this study, mechanical property degradation of both MWCNT/epoxy and SWCNT/epoxy has been measured that were exposed to 3000 thermal cycles.

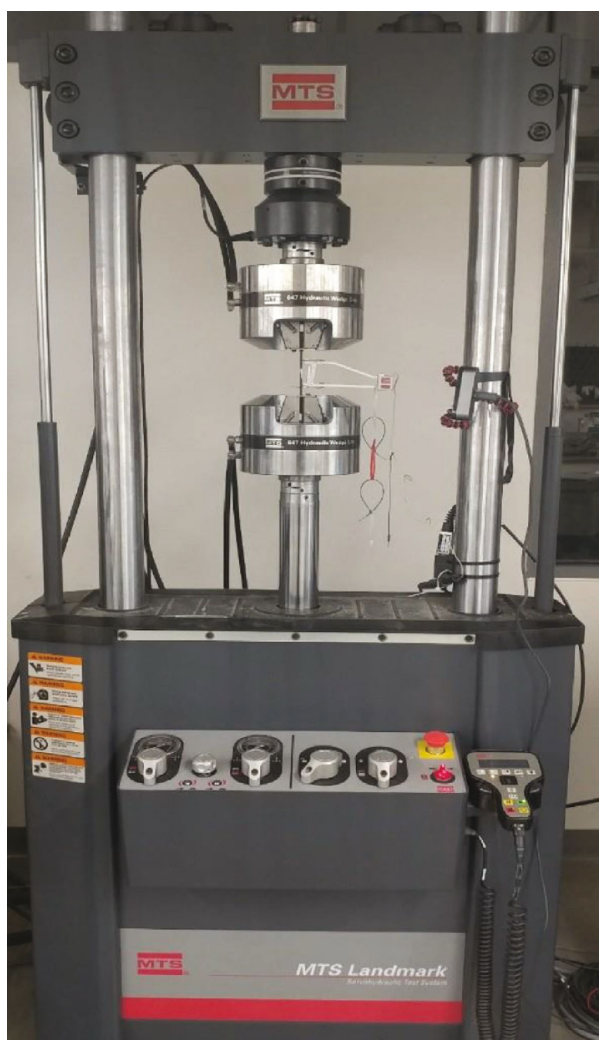

Figure 2: Tensile testing machine.

The difference between this research and the previous studies of the presented authors is that, in the previous studies, the author has developed analytical models based on the experiments which have been conducted by the other authors in the past. In this study, the authors have conducted experiments in the lab to fabricate both SWCNT/epoxy and MWCNT/epoxy and have exposed them to the thermal cycling environment. Additionally, tension and shear tests on the SWCNT/epoxy and MWCNT/epoxy have been conducted by the authors to determine the mechanical properties of the nanocomposites before and after the thermal cycling exposure. In this study, for the first time, the number of thermal cycles has been increased to a maximum 3000 thermal cycles to investigate the effect of higher thermal cycle numbers on the properties of both SWCNT/epoxy and MWCNT/epoxy.

In this research, the effect of thermal cycling on the tensile and shear strength, maximum displacement, ultimate strain, and modulus of elasticity of CNT-reinforced epoxy has been investigated. The details for performing the research and conducting the experiments are included in the following sections.

\section{Problem Formulation}

The objective of this research was to determine the effects of thermal cycling on mechanical properties of epoxy and CNT-reinforced epoxy matrix composites. For this purpose, 


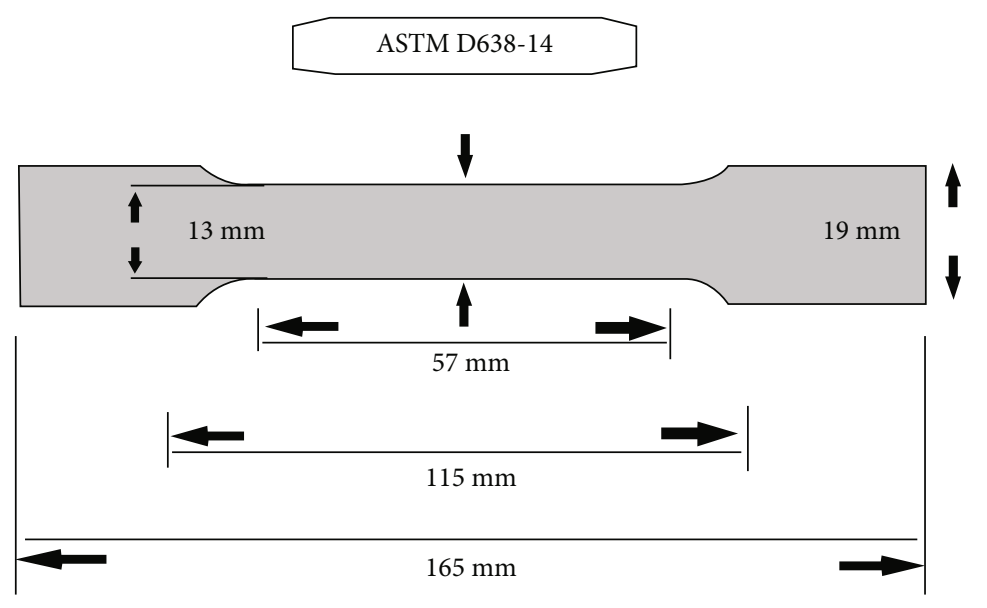

FIGURE 3: Geometry and dimensions of the dog bone specimens which have been used in tension test based on the ASTM D638-14 [14].

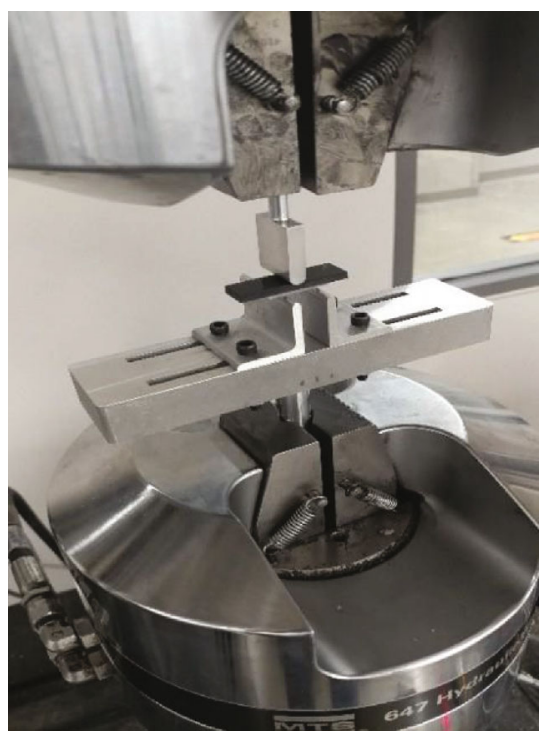

Figure 4: Short-beam test machine.

the first step was to produce epoxy, single-wall CNT(SWCNT-) epoxy, and multiwall CNT- (MWCNT-) epoxy nanocomposites. The concentration of SWCNT and MWCNT reinforcement used was $0.5 \mathrm{wt} . \%, 1.0 \mathrm{wt} . \%$, and $1.5 \mathrm{wt} . \%$, respectively. The $254 \times 254 \mathrm{~mm}$ and $3.0 \mathrm{~mm}$ thick composite plates were subjected to 1500 and 3000 thermal cycles. Thermal cycles were in the range of room temperature to about $85 \%$ of the glass transition temperature $\left(0.85 T_{g}\right)$ of the epoxy. After exposure of the plates to thermal cycles, appropriate test specimens were made as detailed in a later section and mechanical properties of the samples were measured and compared with the mechanical properties of the samples before the cyclic thermal exposure. In this study, for measuring the mechanical properties, tensile and short-beam shear tests were utilized to evaluate the degradation in tensile and shear strengths as compared to nascent specimens not subjected to thermal cycles.

\section{Experimental Procedures}

3.1. CNT-Epoxy Composite Plate Fabrication and Exposure to Thermal Cycling Procedure. MWCNTs were obtained from "US Research Nanomaterials, Inc." The outer diameter of the purchased MWCNTs is $20-30 \mathrm{~nm}$. The SWCNTs were obtained from OCSiAl company. The outer dimeter of the SWCNTs is about $2 \mathrm{~nm}$. Furthermore, the epoxy 2020 was obtained from Fibreglast company. According to the manufacturer's data, the maximum postcure temperature that could be applied to this epoxy is 93 Celsius.

For fabricating CNT-epoxy plates, the first step would be to add $0.5,1$, or $1.5 \mathrm{wt} . \%$ MWCNT or SWCNT to epoxy in a beaker and mix them with a glass rod and then degas the mixture. The second step was to use ultrasonicator to disperse the MWCNT or SWCNT uniformly into the epoxy. The ultrasonicator equipment which has been used to mix the CNTs with epoxy is shown in Figure 1. The third step was to add a hardener to the mixture and mix them with glass rod again. Finally, the ultrasonicator equipment should be used again to make sure that the distribution of the CNTs within the epoxy is uniform.

After the CNT-epoxy mixture is provided either with SWCNT or MWCNT followed by the procedure mentioned above, the mixture was poured into a mold and cured at $32.2^{\circ} \mathrm{C}$ for 22 hours. The dimensions of the aluminum mold are $254 \times 254 \times 3.0 \mathrm{~mm}$. After the CNT-epoxy nanocomposite is fabricated, it was subjected to thermal cycling. Thermal cycling was from room temperature $\left(25^{\circ} \mathrm{C}\right)$ to $0.85 T_{g}$ of the epoxy $\left(65^{\circ} \mathrm{C}\right)$. The glass transition temperature has been determined by using differential scanning calorimetry (DSC) and measured to be $76^{\circ} \mathrm{C}$. Two sets of fabricated epoxy and epoxy-CNT plates were each subjected to 1500 and 3000 cycles of cyclic thermal loading, respectively. The heating part of the thermal cycle has been performed in an air circulating electric oven from $25^{\circ} \mathrm{C}$ to $65^{\circ} \mathrm{C}$ in about 4 minutes. After the samples had reached $65^{\circ} \mathrm{C}$, they are soaked for 1 minute and cooled down to room temperature in about 4 to 5 minutes. For the cooling part of the thermal 


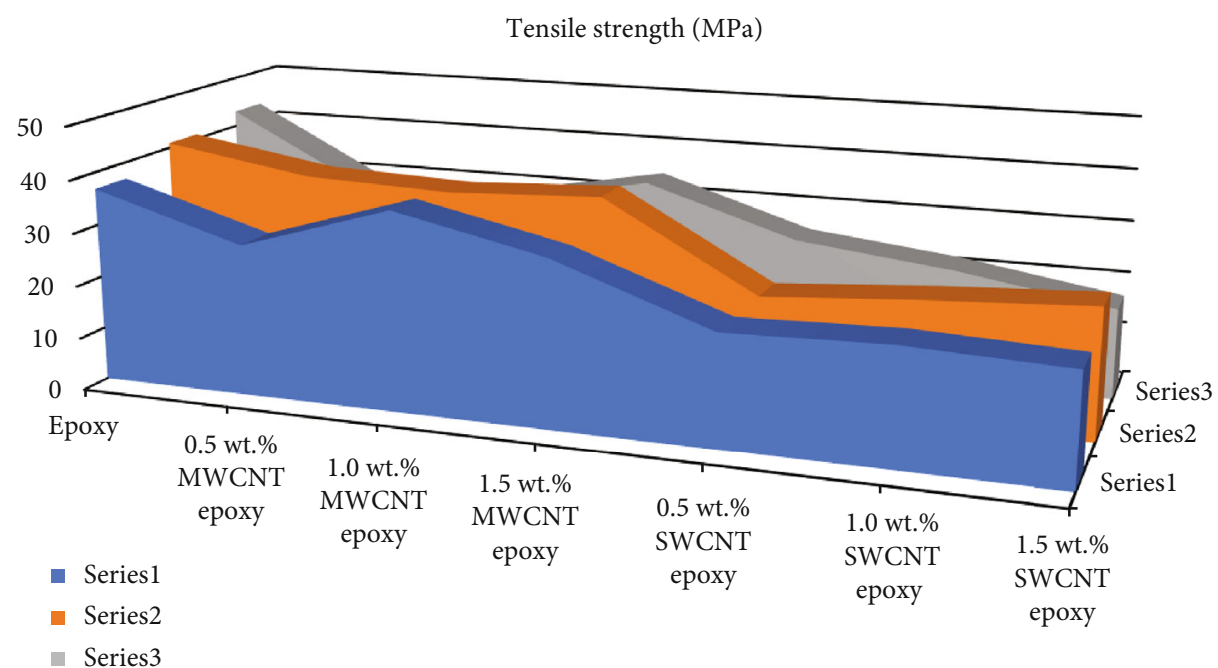

FIGURE 5: Average tensile strength results for CNT-epoxy composite specimens obtained from the tension test.

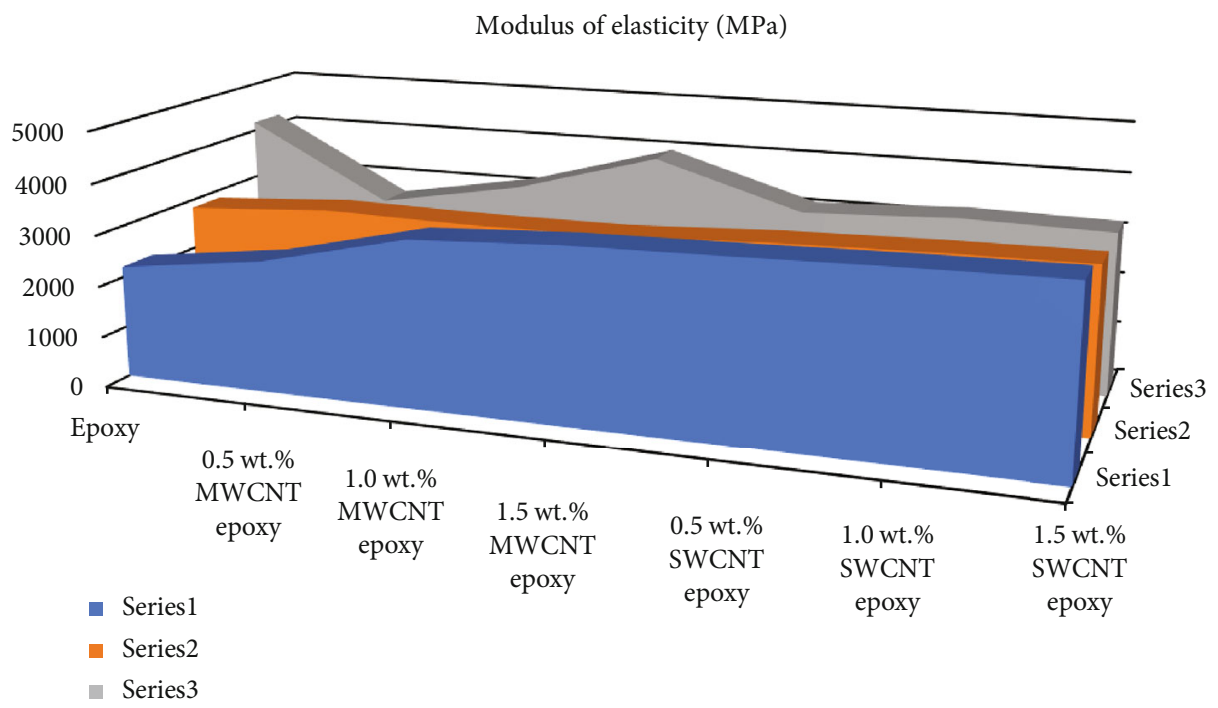

FIGURE 6: Average modulus of elasticity results for CNT-epoxy composite specimens obtained from the tension test.

cycle, forced air cooling with a fan has been used. The temperature at the center of $3.0 \mathrm{~mm}$ thick plate was ensured by inserting a thermocouple from the side of the plate at the midthickness. Tensile test and short-beam test samples were prepared from these processed plates.

3.2. Tensile Test. In this test, the specimen is subjected to uniaxial tension stress until it fails under the ultimate tensile stress. The MTS material test system used in this study is shown in Figure 2.

Dog bone-shaped tensile test specimens were machined from the plates according to the standard ASTM D638-14 and are shown schematically in Figure 3 . The overall length of the tensile specimen is $165 \mathrm{~mm}$, gage length is $50.8 \mathrm{~mm}$, width is $19.05 \mathrm{~mm}$, and the thickness is $3.175 \mathrm{~mm}$. Alumi- num tabs were glued to the specimen ends to avoid crushing of the specimen in the grips. A clip gage was used, as seen in Figure 2, to measure the tensile deformation over a one-inch $(25.5 \mathrm{~mm})$ gage length.

3.2.1. Experimental Procedures. At least five specimens per test condition were tested. Tests at standard laboratory atmosphere of $25^{\circ} \mathrm{C}$ were conducted. In the test, a standard head displacement rate of $2 \mathrm{~mm} / \mathrm{min}$ was used [15]. Specimens were loaded until they fractured.

3.3. Short-Beam Test. ASTM \#D2344 test standard was used to determine interlaminar shear strength for the nanocomposite material when subjected to transverse loading. Interlaminar shear strength can be used to control the quality 


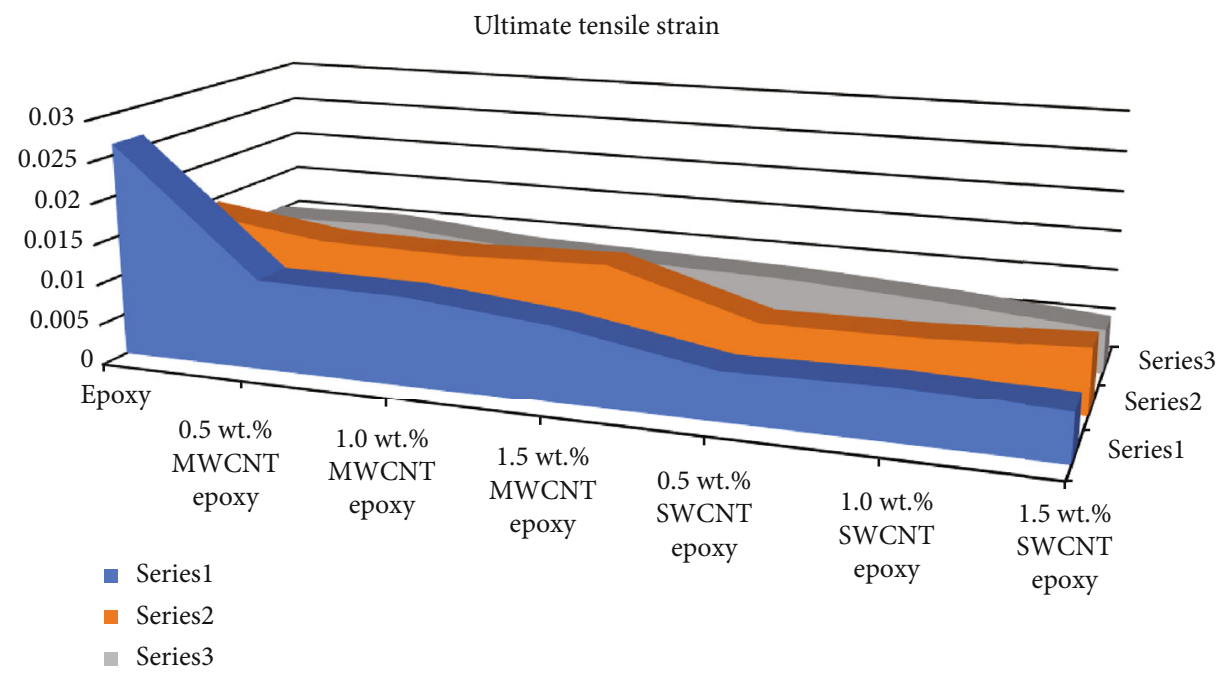

FIGURE 7: Average ultimate tensile strain results for CNT-epoxy composite specimens obtained from the tension test.

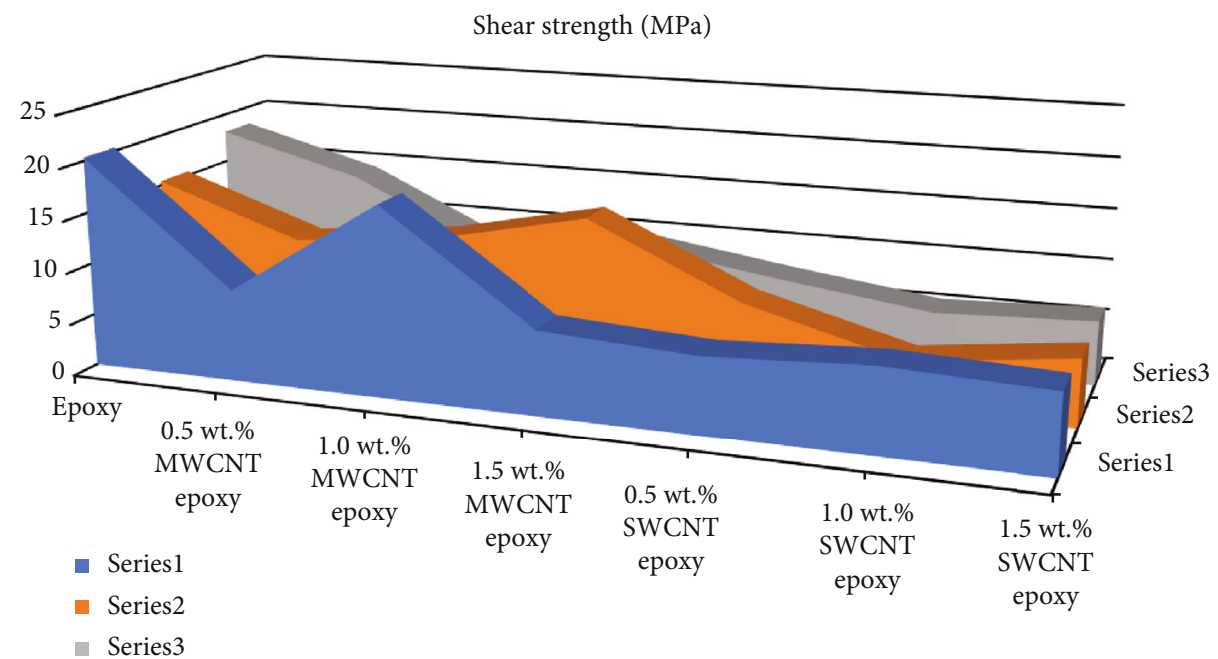

FIGURE 8: Average shear strength results for CNT-epoxy composite specimens obtained from the short-beam test.

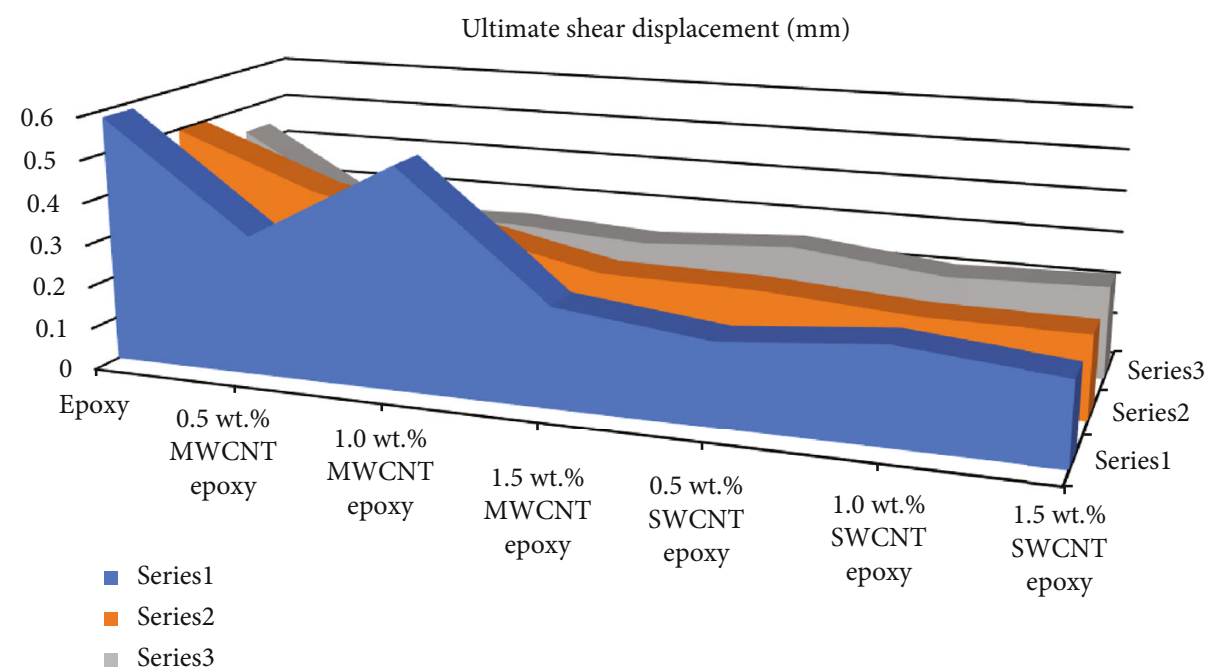

FIGURE 9: Average ultimate shear displacement results for CNT-epoxy composite specimens obtained from the short-beam test. 
Tensile strength standard deviation (MPa)

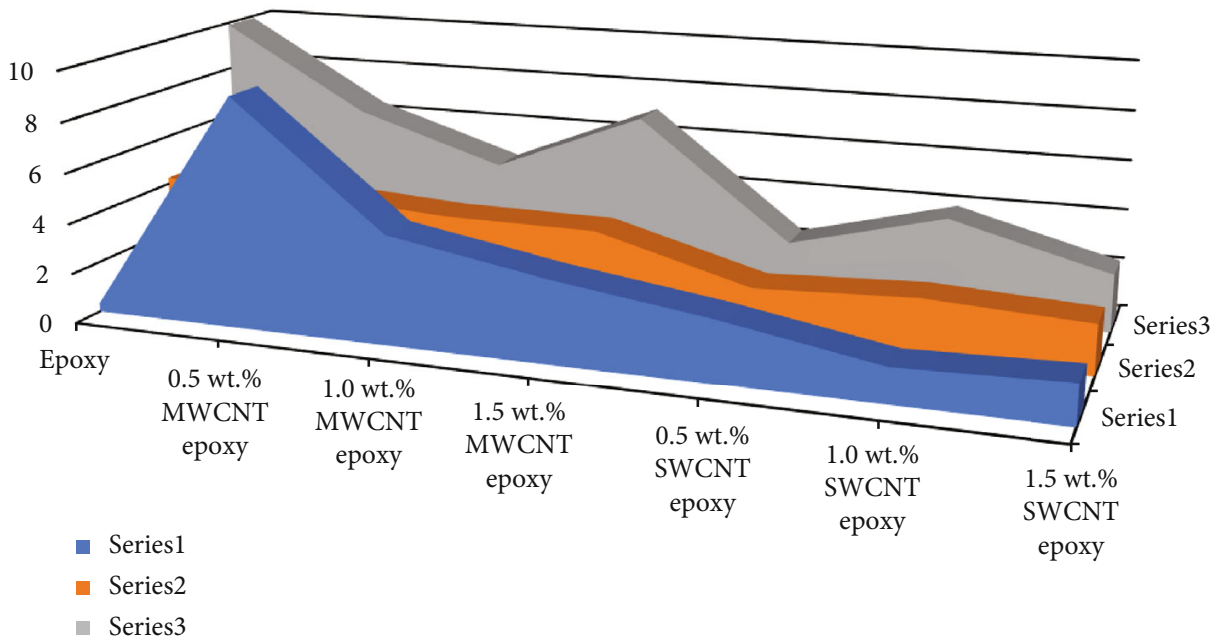

Figure 10: Tensile strength standard deviation obtained from all CNT-epoxy specimens.

Shear strength standard deviation (MPa)

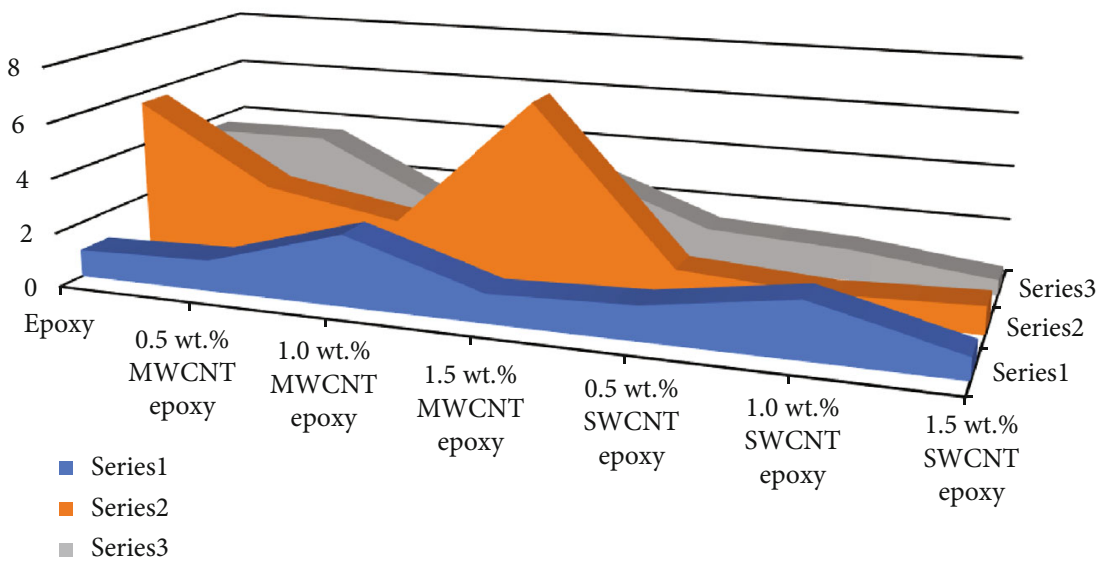

FIGURE 11: Shear strength standard deviation obtained from all CNT-epoxy specimens.

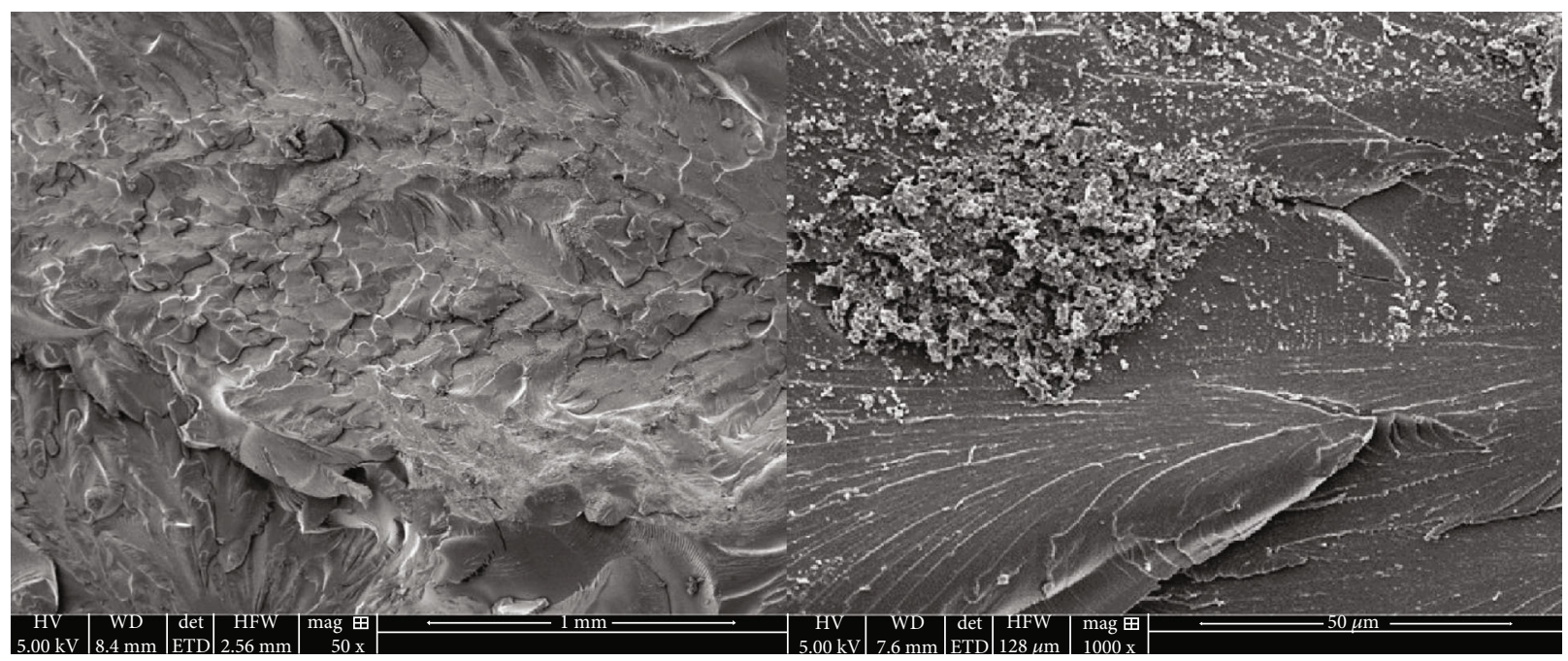

Figure 12: Fracture surfaces due to tensile failure in epoxy at room temperature. 


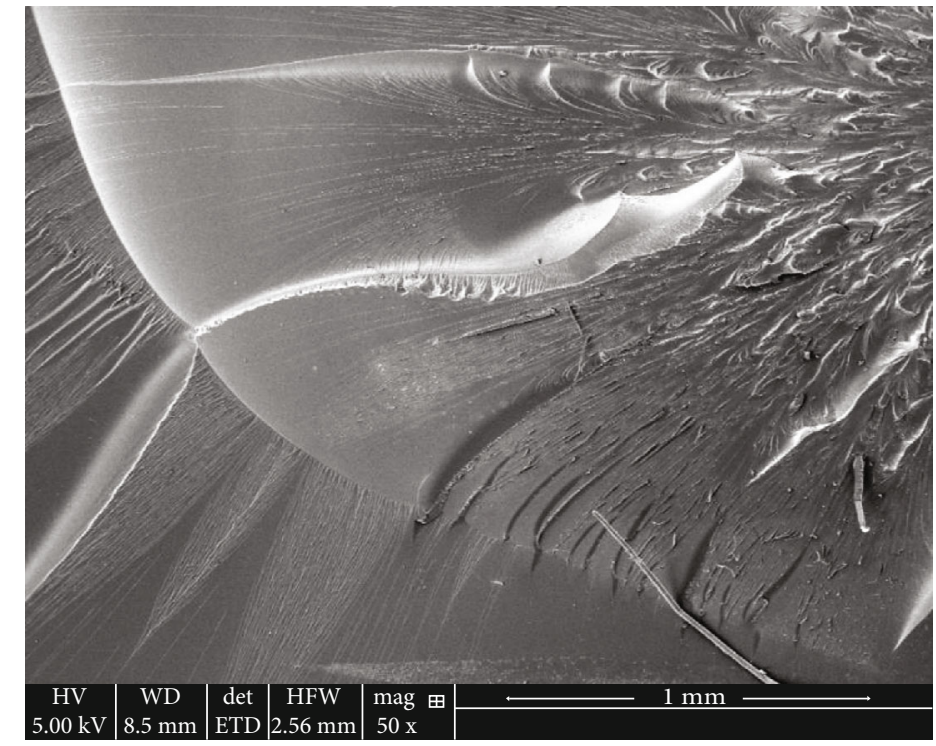

FIGURE 13: Fracture surfaces due to tensile failure in epoxy subjected to 1500 thermal cycles.

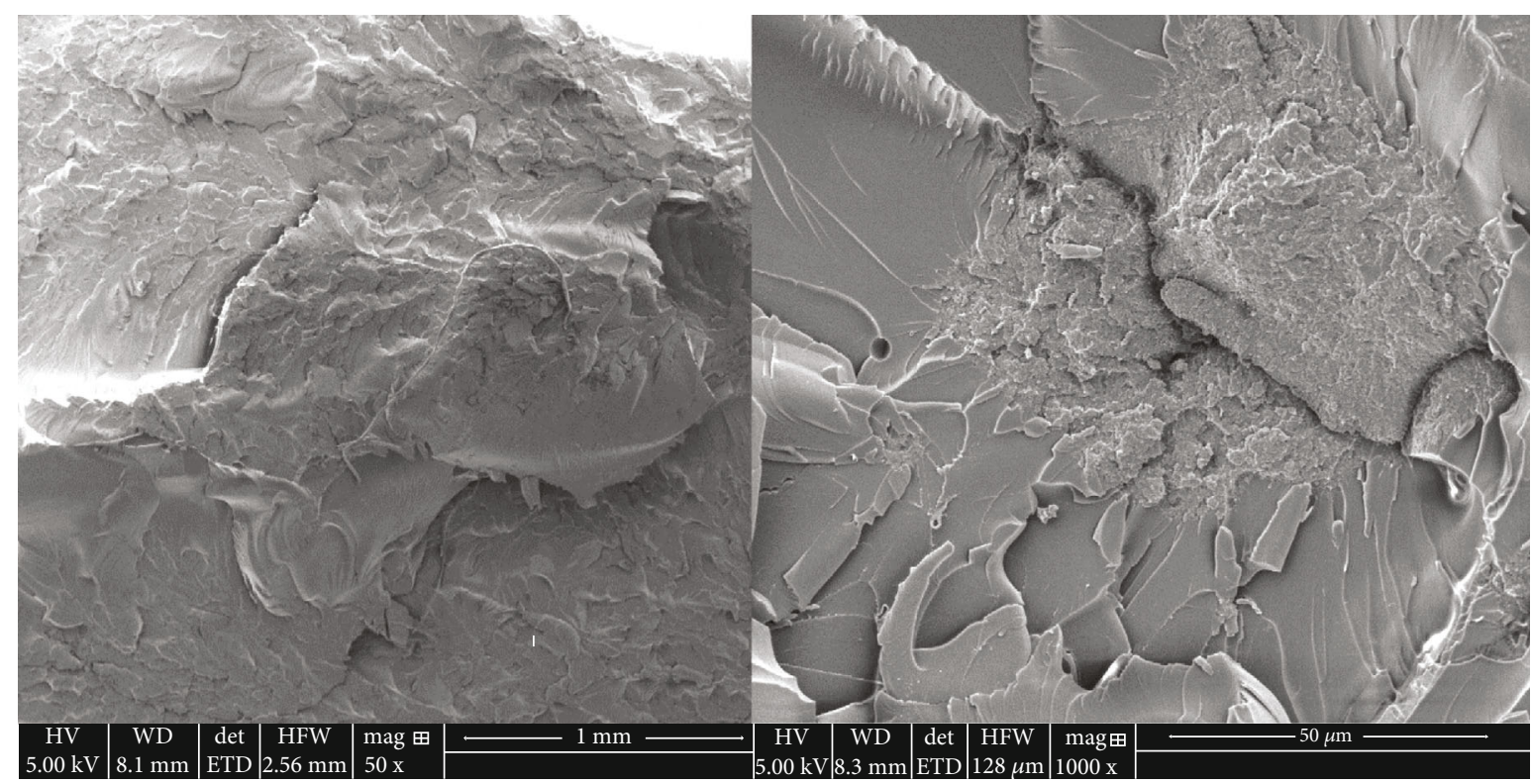

FIgURE 14: Fracture surfaces due to tensile failure in a 0.5 wt.\% MWCNT-reinforced epoxy composite at room temperature.

or to compare the shear strength of different composite materials.

3.3.1. Experimental Procedures. At least five specimens per test condition were tested. The specimen dimensions were according to the respective ASTM standards. Test at standard laboratory atmosphere $25^{\circ} \mathrm{C}$ was conducted by centering the composite sample symmetrically over the fixture of the support, as shown in Figure 4. The applied load to the sample was continued at midspan of the specimen until the sample failed into two parts. In the test, a standard head displacement rate of $2 \mathrm{~mm} / \mathrm{min}$ was used according to the ASTM \#D2344 [16].

\section{Results and Discussions}

All the results which have been obtained from the tension test of dog bone specimens and short-beam shear test specimens are illustrated below. As discussed in the previous sections, below are the results for seven different materials:
(1) Epoxy
(2) 0.5 wt.\% MWCNT-epoxy
(3) 1.0 wt.\% MWCNT-epoxy
(4) 1.5 wt.\% MWCNT-epoxy 


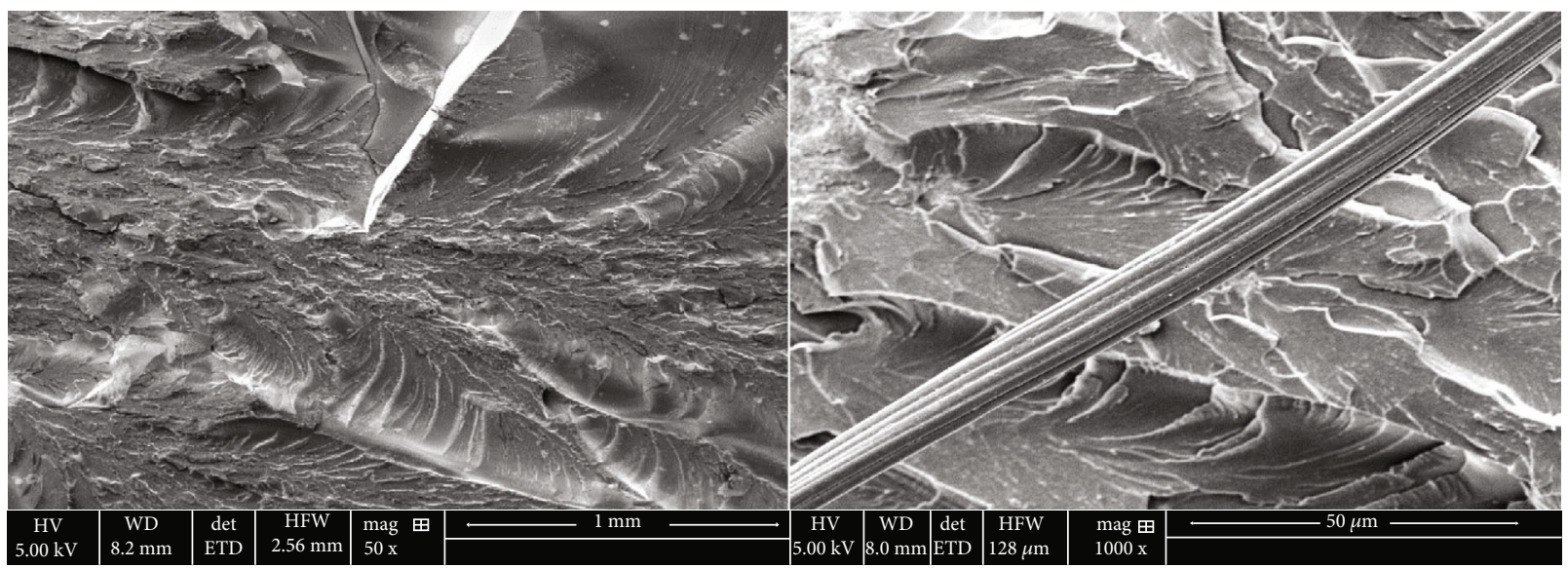

FIGURE 15: Fracture surfaces due to tensile failure in a $0.5 \mathrm{wt} . \%$ MWCNT-reinforced epoxy composite subjected to 1500 thermal cycles.

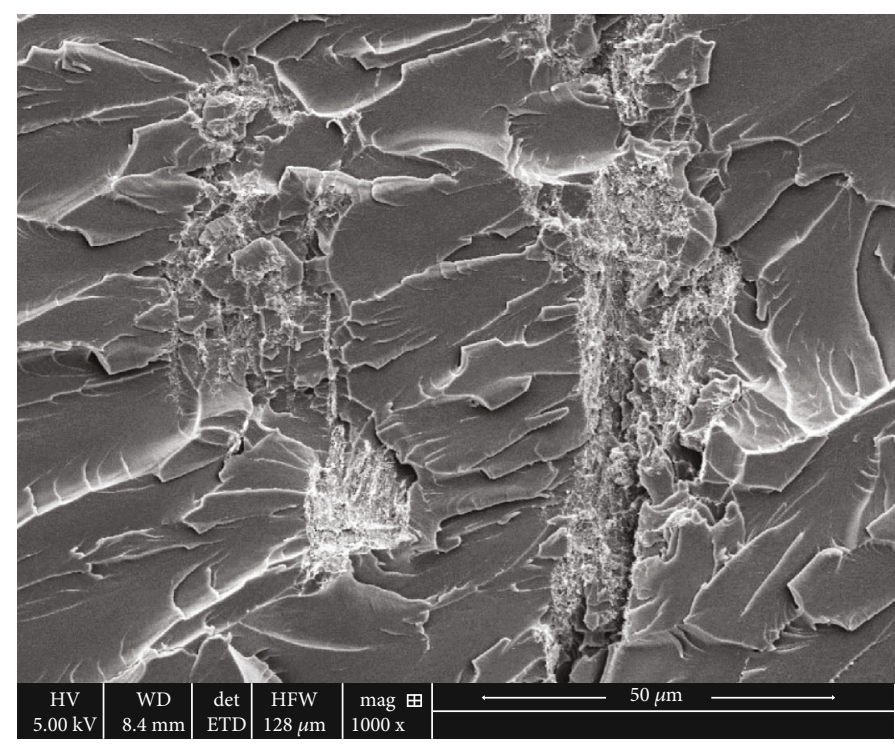

Figure 16: Fracture surfaces due to tensile failure in a $0.5 \mathrm{wt} . \%$ MWCNT-reinforced epoxy composite subjected to 3000 thermal cycles.

(5) 0.5 wt.\% SWCNT-epoxy

(6) 1.0 wt.\% SWCNT-epoxy

(7) 1.5 wt.\% SWCNT-epoxy

For the optimization, all the values for expressing the mechanical properties of all the specimens such as tensile and shear strengths and modulus of elasticity have been rounded to the closest numerical value.

4.1. Tension Test Results. Figures 5-7 provide a summary of the tension test results for epoxy specimens with different CNT reinforcements and number of thermal cycles.

In the following figures, series 1, 2, and 3 represent the 0 , 1500 , and 3000 thermal cycles, respectively.

The pure epoxy material specimens display increasing tensile strength and elastic modulus with increasing thermal cycles. Consequently, the ultimate tensile strain to failure decreases as the epoxy becomes more brittle with increasing thermal cycles.

The mechanical properties of the MWCNT-reinforced epoxy at room temperature (zero thermal cycles) and due to thermal cycling are always lower than the unreinforced epoxy. However, for each concentration of MWCNT, the tensile properties improve at 1500 thermal cycles but degrade as the number of thermal cycles increases to 3000 . It is postulated that the higher number of thermal cycles produce microcracking in the matrix and CNT agglomerates and partial debonding of the CNTs from the epoxy matrix due to relaxation of the compressive stress on the MWCNT due to epoxy shrinkage during curing. With single-wall CNT (SWCNT) reinforcement, the mechanical properties are lower than both the unreinforced epoxy and the MWCNTreinforced epoxy composite. The trend in property changes 


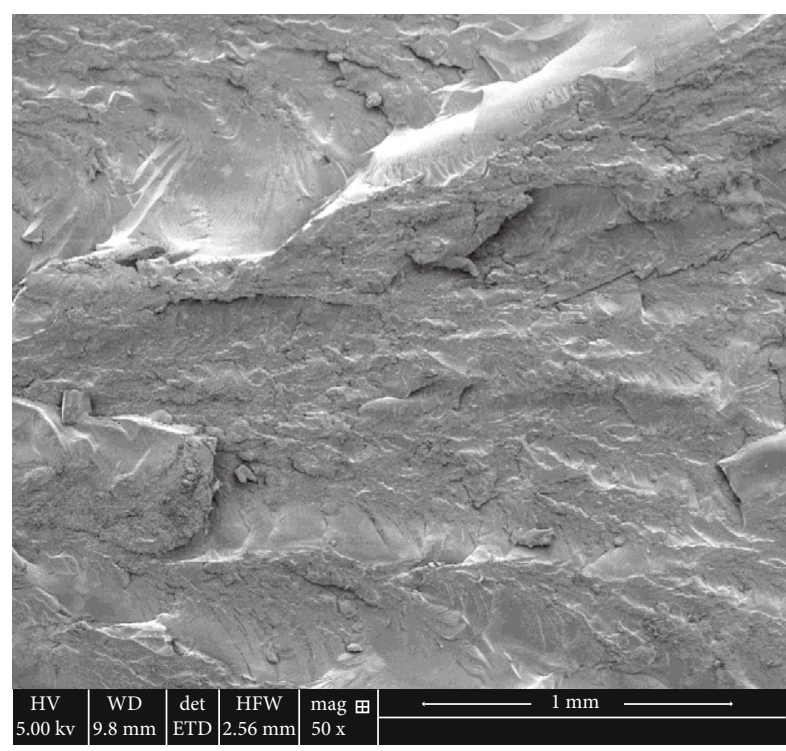

Figure 17: Fracture surfaces due to tensile failure in a $1.5 \mathrm{wt} . \%$ MWCNT-reinforced epoxy composite at room temperature.

with respect to SWCNT concentration and thermal cycles is similar to that with MWCNT specimens. With MWCNT composites, the best properties are obtained with $1.5 \mathrm{wt} . \%$ reinforcement, while for SWCNT composites, the best properties are obtained with 1 wt.\% reinforcement. Apparently, with SWCNT reinforcement, the best properties are obtained for smaller CNT concentration of $0.5 \mathrm{wt} . \%$ for 3000 thermal cycles. However, in the case of SWCNT, the best properties at 3000 thermal cycles is obtained for the highest concentration of $1.5 \mathrm{wt} . \%$.

4.2. Shear Test Results. The shear properties of composite material under transverse loading in the three-point bend loading configuration are shown in Figures 8 and 9. The shear properties are significantly lower with both types of CNT reinforcements and the number of thermal cycles as compared to pure epoxy. The SWCNT reinforcement produces the lowest shear properties for all thermal cycles.

4.3. Statistics Data from the Tensile and Shear Tests. In the figures below, the statistics data that are obtained from the tensile and shear tests are indicated. These statistic data in the table below show the standard deviation of both tensile and shear strengths for each material that was tested.

Variations in the strength values is significant and ranges from a low of about $3.45 \mathrm{MPa}$ to a high of about $20.68 \mathrm{MPa}$ for CNT-reinforced specimens. This variation is even higher in unreinforced epoxy specimens. The variations are lowest in SWCNT-reinforced specimens. These trends are noted for both tensile strength in Figure 10 and shear strength tests in Figure 11. In this preliminary study, it is unclear what are the reasons for the relatively large variations and more detailed investigation on the effect thermal cycles on the matrix and the matrix-CNT interface effects is needed and will be a subject of future effort.

\subsection{Fracture Surface Analysis Using Scanning Electron Microscopy for Various Tensile Test Specimens}

4.4.1. Monolithic Epoxy. At room temperature (RT), fractured paths and surfaces were rough and wavy as seen in Figure 12. The surface has smooth surface regions spread among the rough regions and also small through surface cracks along with spallation is visible at higher magnification of 1000x. A rough fracture surface indicates the potential for larger fracture energy in epoxy at room temperature.

Fracture surfaces of specimens subjected to 1500 thermal cycles had smoother surfaces and consequently smaller regions that were rough as compared to the room temperature specimens, as shown in Figure 13. Smoother fracture surfaces indicate that the thermally cycled epoxy is more brittle with higher tensile strength as compared to the room temperature epoxy.

4.4.2. 0.5 wt.\% MWCNT-Epoxy Composite. At room temperature, fracture surfaces were rough and wavy (at 50x magnification) interspersed with smooth surfaces (at 1000x magnification), as shown in Figure 14. MWCNTs were found to have been dispersed fairly uniformly within the epoxy with small regions of agglomeration. The addition of multiwall CNTs decreased the tensile strength as compared to the room temperature strength of nascent epoxy potentially due to the stress concentration caused by lack of covalent bonding between the epoxy and the CNT.

At 1500 thermal cycles, the tensile strength increased by over $20 \%$ compared to the room temperature specimens. No major changes in the fracture surface characteristics were noted compared to the room temperature fracture specimens except that the surface is wavier with larger peaks and valleys (as in 1000x image of Figure 15) that could cause an increase in the tensile strength. Another potential reason for the increase could be the relaxation in residual stresses due to the thermal cycling. In Figure 15, a CNT bundle can also be seen that has been pulled out and its surface is clean indicating no atomic bonding between the epoxy matrix and the CNT. After 3000 thermal cycles, however, the tensile strength dropped by about $20 \%$ compared to the 1500 thermal cycled specimens. It is postulated that after 3000 thermal cycles, there were increased cracks in the matrix in and around the CNT agglomerates, as seen in Figure 16.

4.4.3. $1.0 w t . \%$ MWCNT-Epoxy. For all thermally cycled specimens, namely, RT, 1500 and 3000 thermal cycles, fracture characteristics were very similar to that observed for the 0.5 wt.\% MWCNT specimens. Also, the tensile strength values are very similar for both the $0.5 \mathrm{wt} . \%$ and $1.0 \mathrm{wt} . \%$ MWCNT specimens.

4.4.4. 1.5 wt.\% MWCNT-Epoxy. At RT, fracture surfaces are somewhat rough with many interspersed smooth and relatively flatter regions, as shown in Figure 17. No other specific cracks are observed.

At 1500 thermal cycles, fracture surfaces have increased in roughness compared to the room temperature specimens, as shown in Figure 18. Furthermore, the CNT agglomeration 


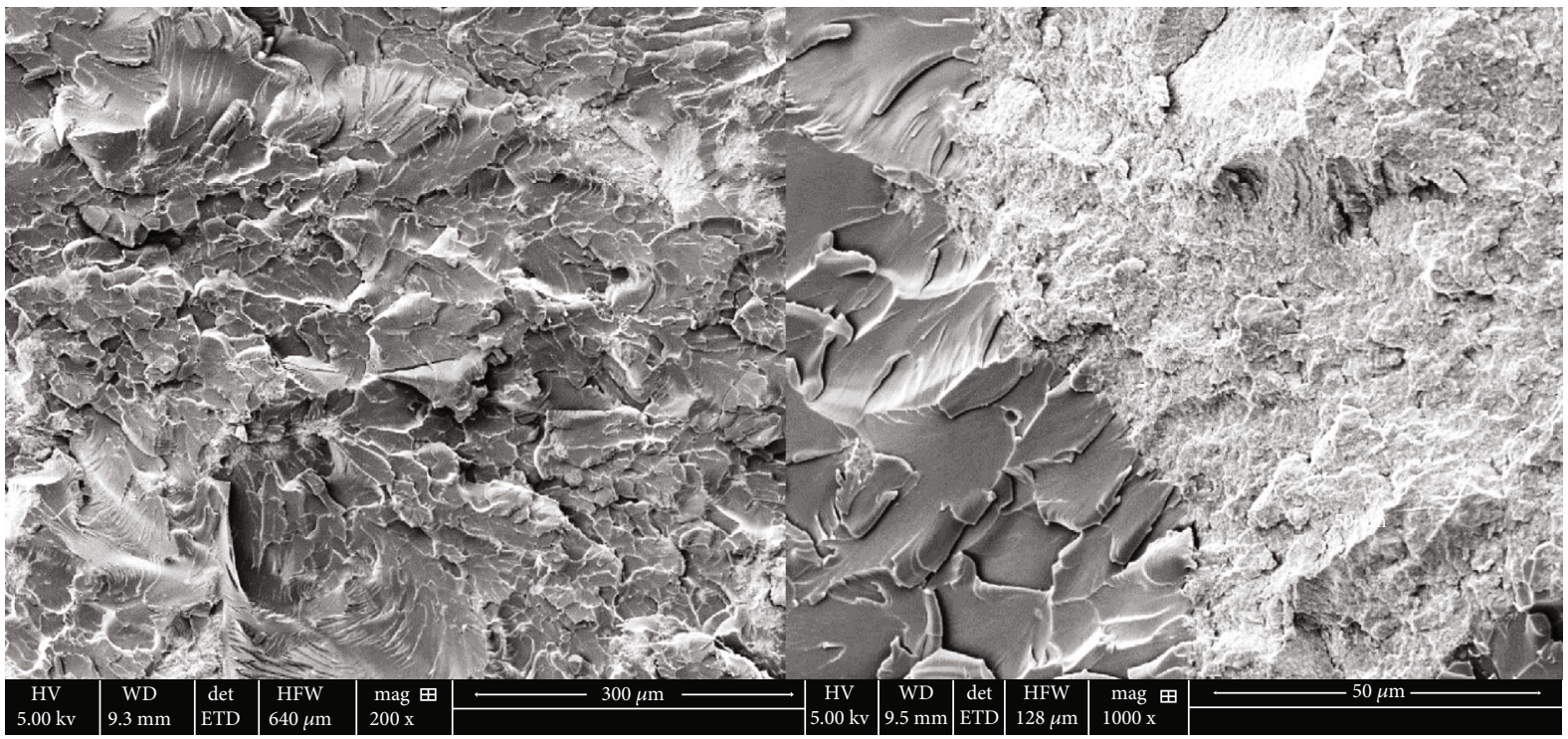

FIGURE 18: Fracture surfaces due to tensile failure in a $1.5 \mathrm{wt} \%$ MWCNT-reinforced epoxy composite subjected to 1500 thermal cycles.

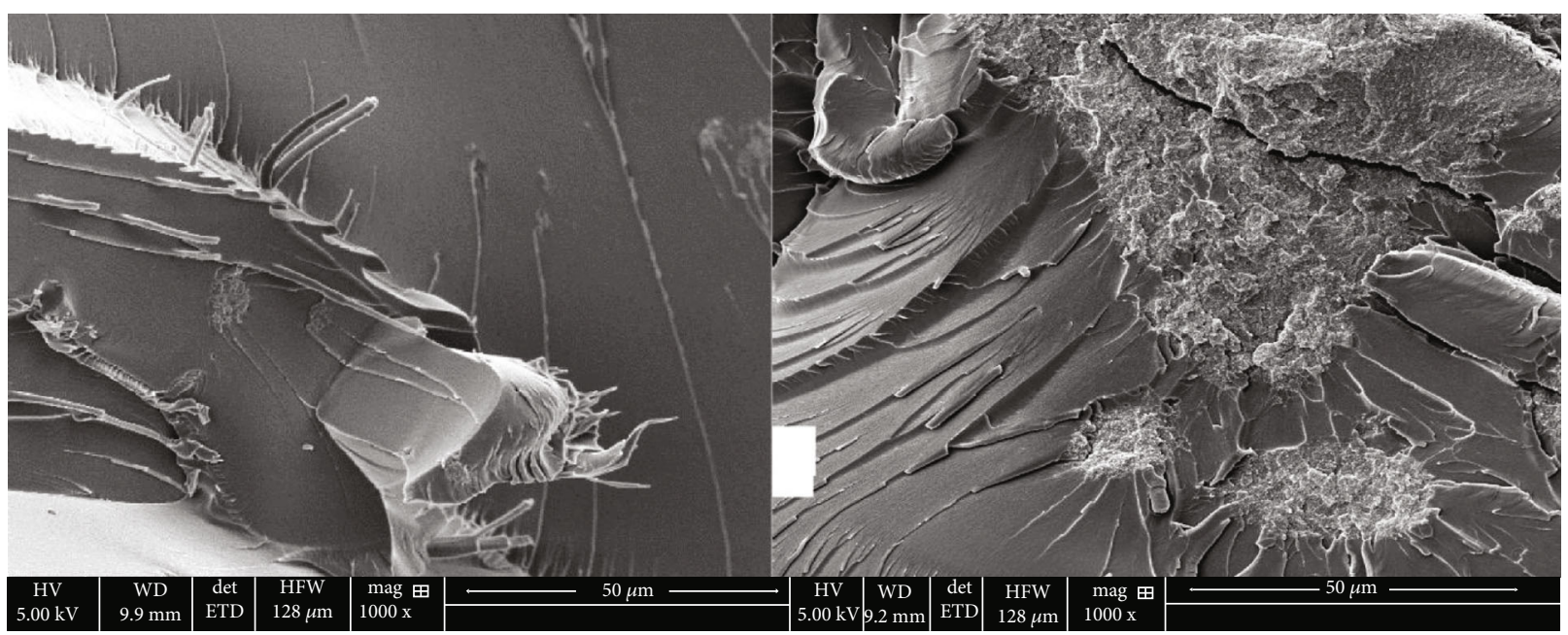

FiguRE 19: Fracture surfaces due to tensile failure in a $1.5 \mathrm{wt} . \%$ MWCNT-reinforced epoxy composite subjected to 3000 thermal cycles.

regions display minor and small length cracks (at 1000x) as compared to lower CNT concentration specimens.

At 3000 thermal cycles, more agglomerated areas have been observed on the fracture surfaces. Furthermore, fracture surfaces are in a complex nonuniform shapes. Additionally, needle-like MWCNTs can be observed on the fractured surfaces, as shown in Figure 19. In the CNT-agglomerated regions, the cracking has increased compared to the 1500 thermal cycled specimens (Figure 18).

4.4.5. SWCNT-Epoxy Composites. Single-wall CNT reinforcement of epoxy produces composites whose mechanical properties are lower than both the unreinforced epoxy and the MWCNT-reinforced composites. Their properties are $40-60 \%$ lower than the epoxy matrix material and also compared to the MWCNT composites. We do not provide scanning microscope pictures for each CNT concentration and thermal cycles but rather provide evidence that potentially explains the reason for the degradation in properties of SWCNT composites. The greater stiffness of the singlewalled CNTs and greater level of agglomeration of CNTs compared to multiwalled CNTs along with greater damage and cracking in the fracture regions leads to lower mechanical properties. As can be seen in Figure $20(50 \mathrm{x}$ and 200x magnification) for 1.5wt.\% SWCNT after 1500 thermal cycles, there is extensive cracking, and furthermore, there is evidence of significant cracking in the regions where CNTs have agglomerated (5000x and 20000x magnification).

Similar trends are noted with potentially greater damage and cracking at 3000 thermal cycles in $1.5 \mathrm{wt} \%$ SWCNT composites, as shown in Figure 21. 

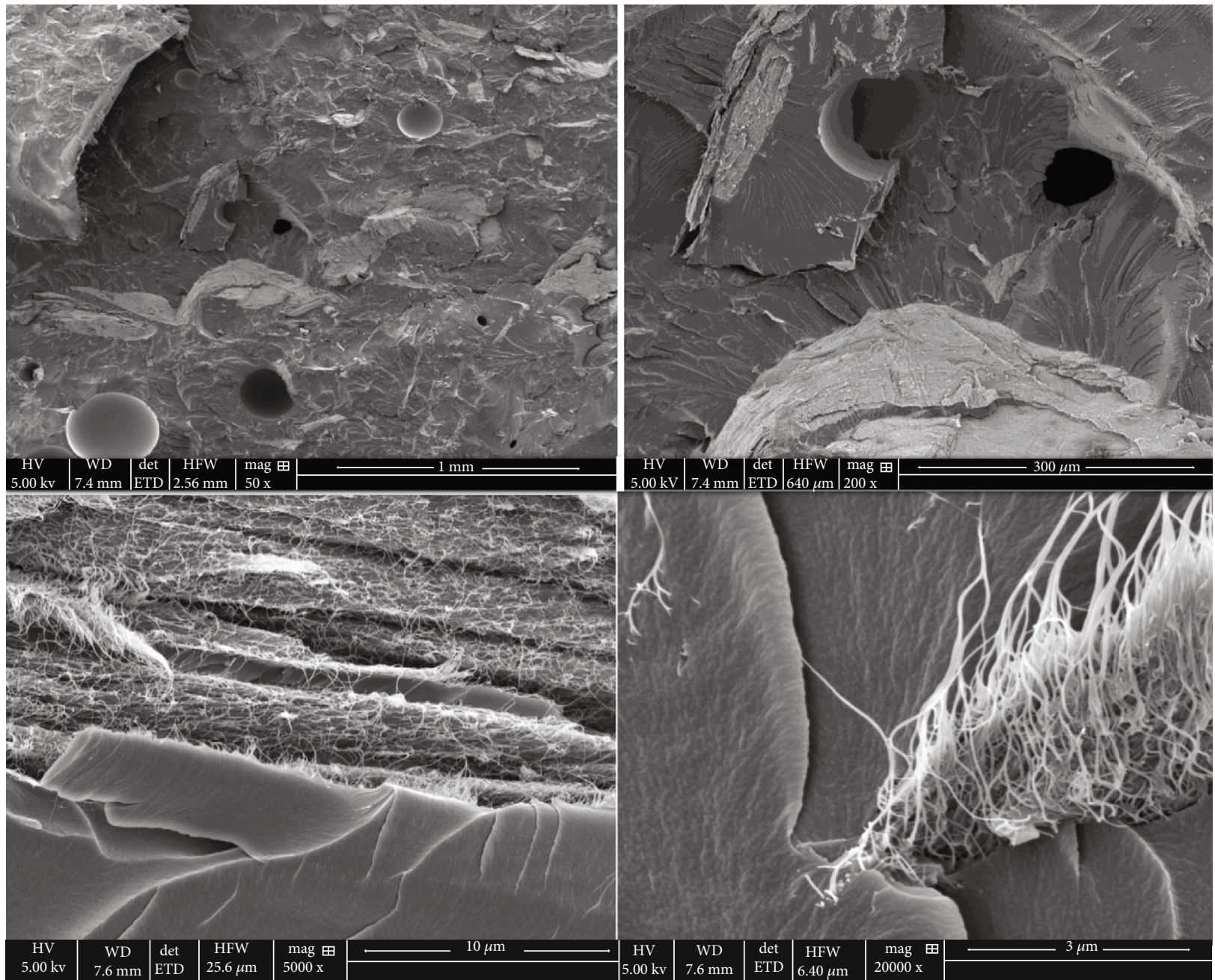

FIGURE 20: Fracture surfaces in a 1.5 wt.\% SWCNT-reinforced epoxy composite subjected to 1500 thermal cycles.

\section{Summary}

Epoxy polymers are used in a large number of applications where thermal cycling is a part of the working environment in addition to mechanical loading. Often, the polymer matrix is reinforced with reinforcements that are in the form of fibers or particles. In this study, carbon nanotubes (CNT) have been used as a reinforcement to produce reinforced epoxy composite plates. The plates were subjected to 1500 and 3000 thermal cycles, and these thermally cycled plates along with as-cured plates at room temperature were tested for their tensile properties and transverse shear properties.

The modulus of elasticity of epoxy and the tensile strength increased with increasing thermal cycles due to greater crosslinking between the polymer chains. Addition of multiwall (MW) CNTs reduced the elastic modulus and the tensile strength for all three CNT concentrations studied as compared to unreinforced epoxy. It was observed that the 1.0 wt.\% MWCNT-epoxy composite subjected to 1500 thermal cycles had the best tensile properties. The addition of single-wall (SW) CNTs as reinforcement to epoxy matrix resulted in composites with mechanical properties inferior to both the monolithic epoxy and the MWCNT-epoxy materials.

The shearing properties of the two CNT-reinforced composites are inferior to the unreinforced epoxy with the SWCNT composite displaying the lowest properties. As in the case of tensile behavior, the $1.0 \mathrm{wt} . \%$ MWCNT composite subjected to 1500 thermal cycles resulted in the best composite material properties.

Based on the results of this study, it can be summarized that the addition of MWCNT produces better mechanical properties compared to the use of SWCNT reinforcement. However, unreinforced epoxy showed the highest mechanical properties. The scanning electron microscope images show the damage mechanisms in the three materials studied, and the various trends have been discussed in the body of the paper. The fracture surfaces in SWCNT specimens show greater damage than in MWCNT composites, which signifies the lower mechanical properties of the SWCNTepoxy composites. In this research, the fracture toughness 


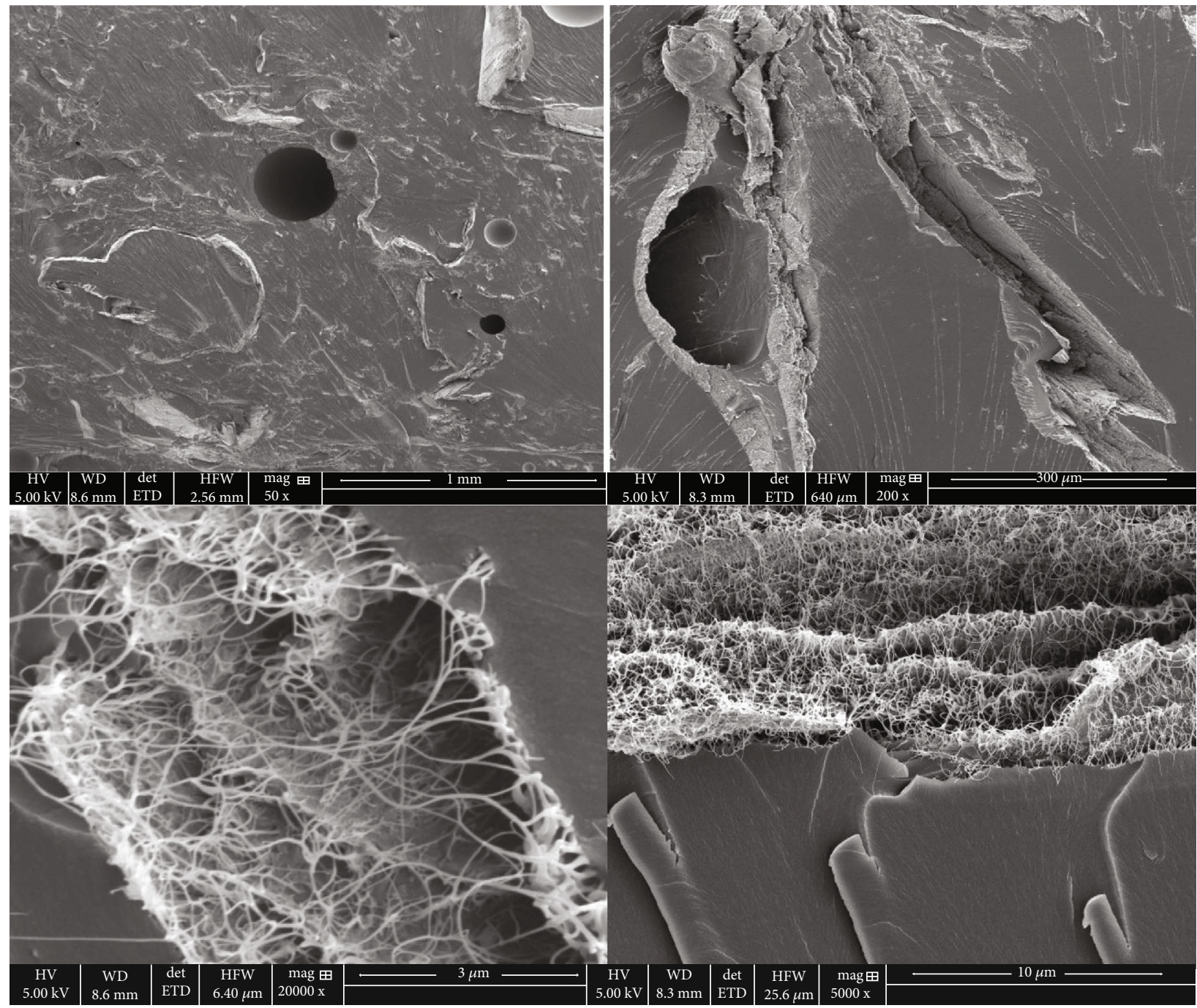

FIGURE 21: Fracture surfaces in a 1.5 wt.\% SWCNT-reinforced epoxy composite subjected to 3000 thermal cycles.

and fracture characteristics were not investigated and would be studied in a future paper. It is postulated that the CNTreinforced composites could show fracture toughness that is higher than the unreinforced epoxy, and hence, the former would be more resilient materials.

\section{Data Availability}

The data used to support the findings of this study are included within the following references [7, 13-16].

\section{Conflicts of Interest}

The authors declare that they have no conflicts of interest.

\section{Acknowledgments}

The authors would like to thank Dr. Sarah Orton, Professor of Civil and Environmental Engineering Department, and Mr. Rupesh Devapati, graduate research assistant in mechanical engineering department, in University of Mis- souri, for their assistance with conducting material testing on the MTS machine.

\section{References}

[1] S. Iijima, "Helical microtubules of graphitic carbon," Nature, vol. 354, no. 6348, pp. 56-58, 1991.

[2] T. R. Frømyr, F. K. Hansen, and T. Olsen, "The optimum dispersion of carbon nanotubes for epoxy nanocomposites: evolution of the particle size distribution by ultrasonic treatment," Journal of Nanotechnology, vol. 2012, Article ID 545930, 14 pages, 2012.

[3] J. Brown, T. Hajilounezhad, N. T. Dee, S. Kim, A. J. Hart, and M. R. Maschmann, "Delamination mechanics of carbon nanotube micropillars," Applied Materials \& Interfaces, vol. 11, no. 38, pp. 35221-35227, 2019.

[4] T. Hajilounezhad, D. M. Ajiboye, and M. R. Maschmann, "Evaluating the forces generated during carbon nanotube forest growth and self- assembly," Materialia, vol. 7, article $100371,2019$.

[5] T. Hajilounezhad and M. R. Maschmann, "Numerical investigation of internal forces during carbon nanotube forest 
selfassembly," in International Mechanical Engineering Congress and Exposition, Pittsburgh, PA, U.S.A, November 2018.

[6] T. Hajilounezhad, Z. A. Oraibi, R. Surya et al., "Exploration of carbon nanotube forest synthesis-structure relationships using physics-based simulation and machine learning," in 2019 IEEE Applied Imagery Pattern Recognition Workshop (AIPR), pp. 18, Washington, DC, USA, 2019.

[7] A. Anvari, "The influence of CNT structural parameters on the properties of CNT and CNT- reinforced epoxy," International Journal of Aerospace Engineering, vol. 2020, Article ID 4873426, 14 pages, 2020.

[8] K. Barri, B. Jahangiri, O. Davami, W. G. Buttlar, and A. H. Alavi, "Smartphone-based molecular sensing for advanced characterization of asphalt concrete materials," Measurement, vol. 151, article 107212, 2020.

[9] A. Rai, N. Subramanian, and A. Chattopadhyay, "Investigation of damage mechanisms in CNT nanocomposites using multiscale analysis," International Journal of Solids and Structures, vol. 120, pp. 115-124, 2017.

[10] G. V. Ramana, B. Padya, R. N. Kumar, K. V. P. Prabhakar, and P. K. Jain, "Mechanical properties of multi-walled carbon nanotube reinforced polymer nanocomposites," Indian Journal of Engineering \& Materials Science, vol. 17, pp. 331-337, 2010.

[11] A. Anvari, "Thermomechanical fatigue of unidirectional carbon fiber/epoxy composite in space," Journal of Engineering, vol. 2020, Article ID 9702957, 5 pages, 2020.

[12] A. Anvari, "Thermal life of carbon structures: from the Earth to after the Titan," International Journal of Aerospace Engineering, vol. 2018, Article ID 7628614, 6 pages, 2018.

[13] S. Y. Park, H. S. Choi, W. J. Choi, and H. Kwon, "Effect of vacuum thermal cyclic exposures on unidirectional carbon fiber/epoxy composites for low earth orbit space applications," Composites: Part B, vol. 43, no. 2, pp. 726-738, 2012.

[14] ASTM International, Standard Test Method for Tensile Properties of Plastics, Astm International, 2014.

[15] J. R. Davis, Introduction to Tensile Testing, ASTM International, Second Edition (\#05106G) edition, 2004.

[16] Annual Book of ASTM Standards, "Standard Test Method for Short-Beam Strength of Polymer Matrix Composite Materials and Their Laminates," 2000, D 2344/D 2344M. 